\title{
Does Advertising Exposure Level Matter? Implica- tions for Experimental Research in Advertising
}

\author{
Wisal Ahmed ${ }^{1}$, Zahid Mahmood $^{2}$, Ayaz Ahmad ${ }^{3}$
}

\begin{abstract}
Advertising researchers have been using test advertisements in asingle exposure experiment. Review of literature, however, reveals that recall and persuasion ability of advertisements varies across different levels of advertising exposures. This study reviews the available literature on ad-exposures and theorizes that three exposures are most suitable for testing optimum effectiveness of advertisements in lab studies. Thesame set of advertisements embedded in a television program was shownin two separate but homogenous groups in single and three ad-exposures and their responses on ad-effectiveness were obtained. The findings of the study reveal that advertisements in three exposures elicited significantly greater brand and ad-recall, more favourable advertisement and brand attitude as well as purchase intent than the same set of advertisements in a single exposure. Collectively, the result of this study provides strong support for three ad-exposures as more appropriatefor testing advertising effectiveness in experimental study setting compared to single exposure.
\end{abstract}

Keywords: Single exposure, three exposures, recall, attitude, purchase intent

\section{Introduction}

In today's era of competition, the role of advertising has increased many folds than ever. As compared to other promotional tools, advertising captures greater chunk of total promotion budget. A large amount of companies' income is spent each year on advertising the company's products and services (Higie\& Sewall, 1991; Kim, 2007). Advertising spending statistics show that only in the United States, the advertising spending were $\$ 70.8$ billion and $\$ 200$ billion during 1988 and 1998 respectively,whereas in 2005, the total advertising spending touched $\$ 475$ billion with a growth rate of $6.7 \%$ a year ${ }^{4}$. Due to such hugespendings, company's concern about the effectiveness of their advertising campaigns has much increased today than ever. However, the advertising effectiveness has always been an important issue in the advertising profession (Jeong, 2004). Review about this debatable issue (the assessment of advertising effectiveness) indicates that different research studies on advertising

1 Institute of Management Sciences, KUST, Kohat. Email: wisalkust@hotmail.com

2 Department of Management Sciences, BAHRIA University, Islamabad. Email: zahid2749@gmail. com

3 Department of Management Sciences, COMSATS, Wah Campus. Email: ayazciit@gmail.com

4 The Economist (2006), Do we have a story for you!, available at http://www.economist.com/ node/5418124 
effectiveness have used different methodologies. Some of the studies, while considering one or two factors necessary for the valid assessment of the advertisements, ignore the other important factors. For instance, some of the previous advertising studies have manipulated the effects of the television program as well as the brand familiarity effects on participants' assessment of the respective advertisements when embedding experimental advertisements in the respective television program (Campbell \& Keller, 2003). However, many other studies have considered some other factors important for valid experimentation (e.g., Ang \& Low, 2000; Kover, Goldberg, \& James, 1995). In line with the same debate, the use of single advertising exposure in previous experimental studies on advertising has always been a major limitation for valid results of the concerned study (Till \&Baack, 2005). There is sufficient amount of literature emphasizing on the number of ad-exposures in which cognition and attitude of advertising viewers reach to peak (Belch, 1982; Sawyer, 1981; Tellis, 1997; Pechman\& Stewart, 1992; Campbell \& Keller, 2003). Based on this available literature, this study argues that unlike previous advertising studies, advertising phenomenon should be studied in more than single advertising exposure as more than one advertising exposure provides a more objective and valid base for precise understanding of the nature of a given advertising issue. However, previous studies investigating the effects of different number of advertising exposures on advertising effectiveness lack consensus about an optimum number of advertising exposure at which both recall and persuasion increase simultaneously. This study attempts to explore the relevant literature on advertising exposure and suggest an appropriate amount of advertising exposure at which the understanding of advertising reachesan optimum level.

\section{Literature Review}

Literature evidencesthe use of different measures of advertising effectiveness. However, in general, the behaviouraldimensions of 'advertising effectiveness focuses on persuasion or and recall being the important factors of ad effectiveness (Ang \& Low, 2000; Till \&Baack, 2005; Groza, 2015). In addition, advertising studies which investigate the causal effects of a stimulus (e.g., effects of cause related marketing on advertising effectiveness) have mostly used lab-experimental study settings. Therefore, to investigate the causal effects of ad-exposures on the assessment of ad- effectiveness and review the relevant literature, this study considers those advertising studies which examine the effects of ad-exposure levels in a laboratory setting. More precisely, this study explores the advertising literature related to the influence of various experience on recall, attitude and purchase intent in a contrived lab-experiment setting.

\subsection{Advertising Exposures and Recall}

To judge the memory performance of advertisements, researchers have used 
consistently recall as one of the important elements of the effectiveness of advertising (Till \&Baack, 2005; Stone, Besser \& Lewis, 2000). The main reason for this is that it measures the likelihood of a brand presence in the minds of consumers(Loudon $\&$ Della Bitta, 2002).Concerning the effects of advertising exposures on consumers' memory, numerous research has demonstrated that exposure levels have a close relationship with consumers cognition which produces higher recall. From research, it is confirmed that higher level of advertising exposures provides greater opportunity to advertising viewers to sense and process the advertising information at a deeper level in their minds. According to Cacioppo and Petty (1979),respondents' recall is significantly higher in three exposures than in a first and second exposure. Moreover, respondents have significantly greater recall of advertisements when exposed to the advertisements more than four times compared to those who are exposed to same advertisements three times. Similar to these results, Sawyer (1981) found that subjects' retriebaility of ad information in three exposures was significantly higher as compared to single and two exposures of the experimental advertisements. The same findings were replicated by Belch (1982) who found that as the number of advertising exposure increases, so as the respondents' recall. Overall, early laboratory studies have found that recall moves upward linearly as the advertising exposures increases from first to six ad seeing (Pechmann\& Stewart, 1992). In line with these arguments, the recall level of advertising viewers is supposed to be significantly higher if they are exposed six times to advertisements than if they watch the same ads for the first time (See Figure 1).

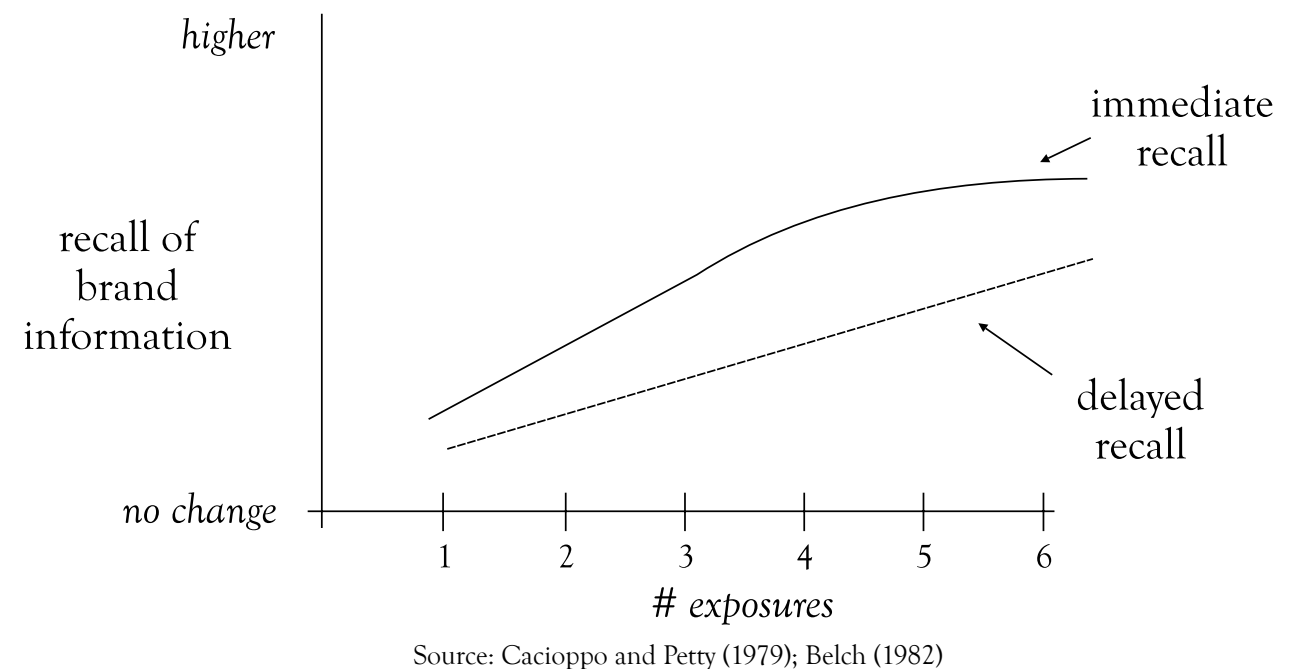

Figure 1: Ad Exposure and Recal 


\subsection{Advertising Exposures and Persuasion}

In addition to the above discussion on the linearly increasing effects of advertising exposures on recall of advertising viewers, literature also states that consumers' cognitive and hence the advertising exposure moderate the attitudinal response of ad viewers. It has been confirmed by studies that viewers understanding of the advertisements gradually goes upward until it touches a certain level of exposure. Beyond that level of exposure, the resulting effects on viewers ad and brand attitude starts downward. According to Krugman (1972), first ad exposure leads to inquisitiveness, ambiguity and lack of recognition about the advertisement, which is referred to "what is it" stage. This stage produces motivation viewers to comprehend the ad message in the second ad seeing. This stage is reffered as "what of it" stage. In the third ad exposure, the adertismenet being watched is evaluated in altogather. Ccording to Cacioppo and Petty (1979), advertismenet viewrs brand attitude become more favourable when the ad is seen three times, and it becomes weekly favourable on next occurring exposures. Similalry, according to Calder and Sternthal (1980), consumers positive thoughts in mind are created in three ad seeing which further produces positive ad and brabd attitude. After three advertising exposures, negative thoughts start in viewers' minds which make their attitude unfavourable. According to Sawyer (1981), the intial two advertisement seeing procures low recall and week positive attitudinal response. However, both the attitude and recall gets optimum on third exposure. Belch (1982) substantiated similar findings. This has been shown in figure 2 .

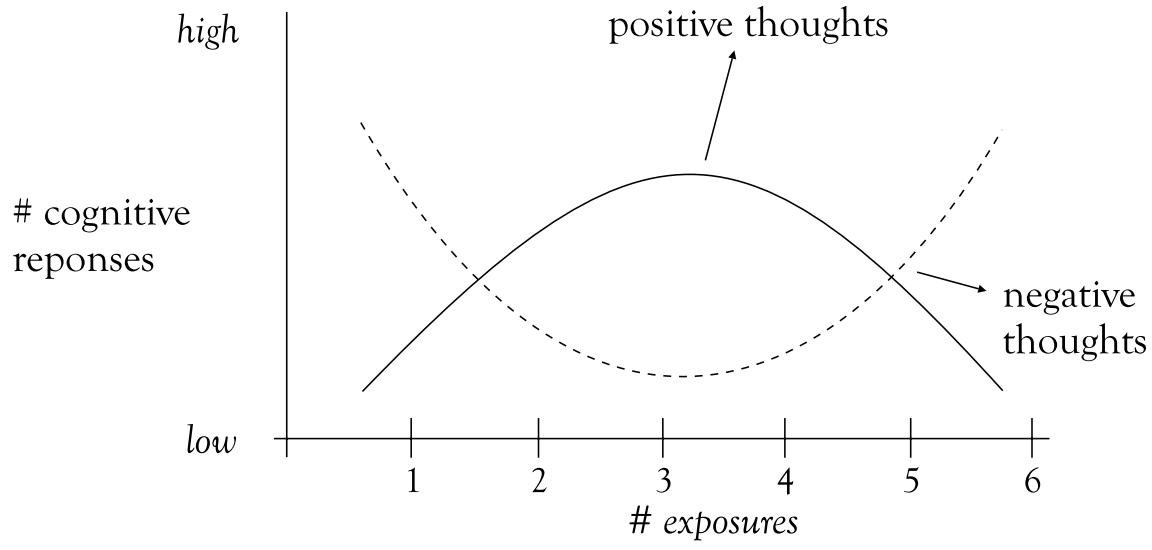

Source: Calder and Sternthal (1980); Belch (1982)

Figure 2: Ad Exposure and Cognition

According to Pechman and Stewart (1992), even the first advertising seeing produces favourable effect. However, for optimal understanding, it is suggestd that researchers shold rely on three ad exposures. According to Naples (1997), optimal advertising exposures in earlier research work stands at three ad seeing and after which 
the effectiveness of advertisement starts dimisnhing. This substantiates the results of Sawyer (1981). Accoording to Sawyer (1981), the consumers advertising responses gets the shape of the Inverted- $U$ which means that earlier ad seeing leads to positive effects which resultantly optimizes at third seeing and beyong third seeing, it results into negative response. In line with these arguments, it can be implied that respondents who obtain three exposures of the experimental advertisements are supposed to have a more positive advertisement and brand related attitude than those who are exposed to the same advertisements only once.

\subsection{The Intersection of Advertising Exposure Level, Recall and Persuasion}

The majority of studies concludes that viewers' recall increases from low on the first two seeing, then high when the ad is seen thrice and recall optimizes on sixth exposure after which recall gradually decreases. However, early laboratory studies found that peak cognitive response reaches on third exposure and hence positive attitudinal response from advertising viewers. In the first two exposures, the advertisements produce negative cognitions and less favourable attitude, however, third exposure produces positive effects on cognitions and hence leads to more favourable attitude (Cacioppo\& Petty, 1979; Sawyer, 1981). Beyond three exposures, the negative thoughts in viewers' minds outnumber the positive thoughts which exert negative effects on their attitude.

In line with the above argumentation, it may be possible that with more than three exposures, the attitude of advertising viewers may become negative; however, recall will steadily increase till the sixth advertising exposure. Therefore, the right amount of advertising exposure should be one which exerts the maximum positive effects on viewers' attitude as well as produce sufficient amount of recoil. In other words, the right amount of advertising exposure should be the point where recall while linearly increasing with the number of exposures, intersects the positive cognition and attitudinal response. This has been depicted in figure 3 below.

As shown in figure 3, the cognitive response of advertising viewers and hence their attitudinal response towards the respective advertisements touches the linearly increasing curve of recall on the third exposure. Beyond third exposure, cognitive response becomes negative, which further affects the attitude of advertising viewers negatively. In line with this argumentation, this study argues that three exposures, being a more stable and valid ground for obtaining peak response of research participants, should be used for investigation of an advertising phenomenon as compared to single advertising exposure where the viewers' response still remains in the process of maturation. 


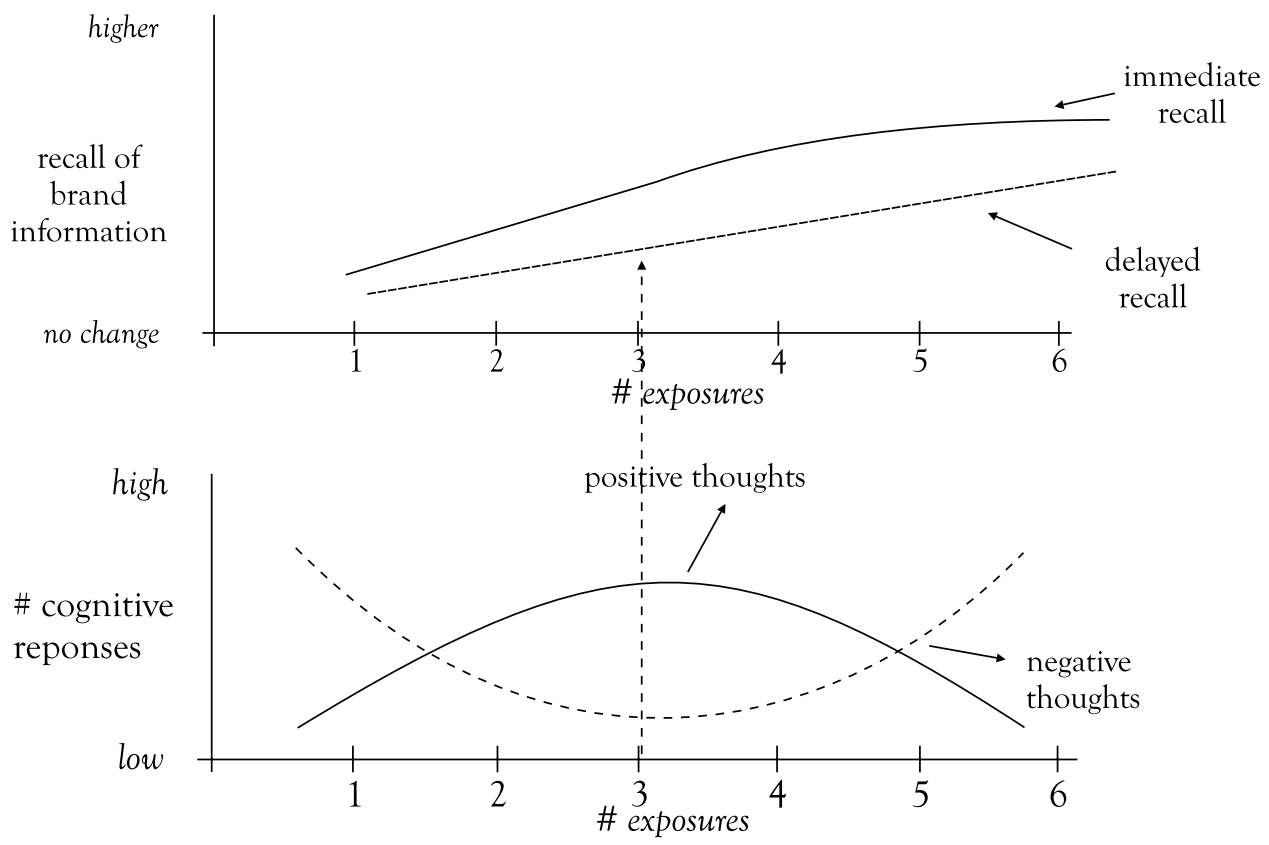

Source: Ahmad, Mahmood, Ahmad and Saeed (2015)

Figure 3: Optimum Level of Advertising Exposure and its Effects on Persuasion and Recall.

\subsection{Hypotheses}

Based on the literature discussion, the following hypotheses are deduced.

$\mathrm{H}_{1}$ : The experimental advertisements will lead to significantly higher unaided brand recall in three ad-exposures than single exposure.

$\mathrm{H}_{2}$ : The experimental advertisements will lead to significantly higher unaided ad recall in three ad-exposures than single exposure.

$\mathrm{H}_{3}$ : The experimental advertisements will lead to significantly more favourable advertisement attitude in three ad-exposures than single exposure.

$\mathrm{H}_{4}$ : The experimental advertisements will lead to significantly more favourable brand attitude in three ad-exposures than single exposure.

$\mathrm{H}_{5}$ : The experimental advertisements will lead to significantly greater purchase intent in three ad-exposures than single exposure. 


\section{Methodology}

Randomized control group experimental design was used to test the theory of the study. Being a more homogenous group of subjects which is cruicial for internal validity of an experiment, data from 177 business students was collected. The participation in research was though subject to the willingness of research partcipants. Subjects were randomly assigned to each of the two experimental groups: single and three advertising exposures. Total twelve advertisements with each two ads representing one similar product category were edited by a professional editor for unfamiliar brand names and were embedded in a television program. Serious attention was given to the sequence of the advertisements so that effects of first and last seen advertisement could be controlled. After watching television program and embedded advertisements, subjects asked to fill the questionnaires measuring unaided brand and advertisement recall (Till \& Baack, 2005) and the subjects' brand and advertismenet attitude (Baker \& Kennedy, 1994; Burke \&Edell, 1986) and purchase intent (Pelsmacker, 1998). The data was analysed for exposure wise ad-effectiveness as well as the interactive effects of ad-exposure levelsusing Analysis of Variance and Multivariate Analysis of Variance.

\section{Analysis \&Results}

Multivariate Analysis of Variance (MANOVA) was used as most suitable analysis tool to analyse the responses of advertising viewers on different measures of advertising effectiveness in single as well as three exposures. Test statisticsare given in table 1 below.

Table 1: Ad-Exposure Wise Response on Advertising Effectiveness Measures

\begin{tabular}{|c|c|c|c|c|}
\hline Measure & Mean 1-Exposure & Mean 3-Exposures & F & Sig \\
\hline Unaided Brand Recall & 0.32 & 0.44 & 69.47 & 0.001 \\
\hline Unaided Adv-Recall & 0.24 & 0.37 & 73.39 & 0.001 \\
\hline Advertisement Attitude & 4.79 & 5.49 & 81.19 & 0.001 \\
\hline Brand Attitude & 4.74 & 5.28 & 70.87 & 0.001 \\
\hline Purchase Intent & 4.39 & 4.99 & 31.68 & 0.001 \\
\hline
\end{tabular}

Hypothesis one stated that advertisements will lead to significantly greater unaided brand recall in three exposures than single exposure. To investigate the interactive effects of exposure level (single $\mathrm{Vs}$ three exposures) on unaided brands recall, descriptive statistic revealed that research subjects having seen the advertisements thrice recalled the greater number of brand names (Mean: 0.44) as compared to those who watched advertisements only once (Mean: 0.32). The results of MANOVA revealed that mean unaided brand recall is also significantly different across the two exposure levels and hence, $\mathrm{H}(1)$, suggesting the incremental role of three advertising exposures 
for brand names recall compared to single ad-exposure was therefore supported $(\mathrm{F}=$ 69.47, $\mathrm{p}<0.05)$.

Hypothesis two stated that subjects in three advertising exposures will describe the features of the greater number of advertisements as compared to those who are exposed to these advertisements only once. The descriptive statistics revealed that subjects recalled a greater number of advertisements in three exposures as compared to single exposure. The MANOVA results also found that mean advertisement recall significantly differ across single and three exposures (Mean 3-Exposures: 0.37, Mean 1-Expsoure: 0.24; $F=73.39, p<0.05)$. Based on this statistical evidence, hypothesis two was also substantiated.

Hypothesis four was based on the proposition that since favourable advertisement attitude lead to positive brand attitude; as well as the superior role of three ads-exposures than single exposure in forming more favourable advertisement or brand attitude, it was hypothesized that subjects' positive advertisement attitude in three ad-exposures will also produce more favourable brand attitude in three ad seeing than if the ad is seen once. Parallel with the result of hypothesis three, subjects' brand attitude was also found significantly more positive in three ad seeing than subjects' brand attitude a single exposure (Mean 1-Exposure: 4.74, Mean 3-Exposure: 5.28; F $=70.87, p<0.05)$. Hence, hypothesis four was also substantiated.

Hypotheses five predicted positive brand attitude also produce greater purchase intention, therefore, advertisements, developing a greater positive brand attitude in three exposures will also produce greater purchase intent than advertisements in a single exposure. The obtained responses of research participants in single and three exposures were analysed for purchase intent respectively. The MANOVA result confirmed for a significant mean difference in purchase intent in single versus three exposures respectively. (Mean 1-Exposure: 4.39, Mean 3-Exposures: 4.99; F = 31.68, $p<0.05)$. Hypothesis five was also validated.

\section{Conclusion \& Future Research Directions}

This study investigated the comparative effects of single and three advertising exposures in the assessment of advertising effectiveness. In three advertising exposures as compared to single ad-exposure, significant means' difference was found in viewers' advertising and brand recall, their attitude towards the respective advertisements and brands; and their purchase intent for the advertised brands respectively.

The results of this study in three exposures as compared to single exposure subastantiates the popular theory of advertising exposures stating the superior effect of greater attention and comprehension if the ad is seen in three exposures compared 
to watching of ad once (Cited in Pechman\& Stewart, 1992). This study found that studies pertaining to measuring consumers' brand and advertisement recall, and brand and advertisement attitude should adopt three advertising exposures as a reliable base for advertismenet comprehsion.

As with every research, this research has also certain limitations. One of the limitations of this study is the use of students as the unit of analysis. The use of students in this research was mainly based on the specific experimental requirements of this study; however, it has the genralizbility issue. In future, similalr study could be replicated with other research subjects. Finally, unlike developed countries where university setting is commonly used for experimental research, the lack of tendency towards experimental research among university students in Pakistan may have affected the findings of the study. Hence, it is strongly suggested that such study should be replicated in some developed country to further understand the effectiveness of three advertising exposures as compared to single exposure.

\section{Acknowledgements}

The researcher heartily acknowledges the generous financial support of Higher Education Commission of Pakistan in the completion of the first author's $\mathrm{PhD}$ program of which this study is a major part.

\section{References}

Ang, S. H., \& Low, S. Y. M. (2000). Exploring the dimensions of ad creativity. Psychology and Marketing, 17(10), 835-854.

Baker, S. M., \& Kennedy, P. F. (1994). Death by nostalgia: A diagnosis of context-specific case. Advances in Consumer Research, 21(1), 169-174.

Belch, G. E. (1982). The effects of television commercial repetition on cognitive response and message acceptance. Journal of Consumer Research, 9(1), 56-65.

Burke, M. C., \& Edell, J. A. (1986). Ad reactions over time: Capturing changes in the real world. Journal of Consumer Research, 13(1), 114-18.

Cacioppo, J. T., \& Petty, R. E. (1979). Effects of message repetition and position on cognitive response, recall and persuasion. Journal of Personality and Social Psychology, 37(1), 97-109.

Calder, B. J., \& Sternthal, B. (1980). Television commercial wearout: An information processing view. Journal of Marketing Research, 17(2), 173-186.

Campbell, M. C., \& Keller, K. L. (2003). brand familiarity and advertising repetition effects. Journal of Consumer Research, 30(2), 292-303. 
Groza, P. (2015). Advertising interference: Factors affecting attention to super bowl advertisements and their effectiveness. Marketing Management Journal, (Fall), 123-133.

Higie. R. A., \& Sewall, M. A. (1991). Using recall and brand preference to evaluate advertising effectiveness. Journal of Advertising Research, 31(2), 56-63.

Jeong. (2004). Exploring the impact of advertising on brand equity and shareholder value. Unpublished PhD Dissertation, The University of Texas at Austin.

Kim, K. R. (2007). The Effects of Advertising and Publicity on Corporate Reputation and Sales Revenue: 1985 2005. Unpublished PhD Dissertation, The University of Texas at Austin.

Kover, A. J., Goldberg, S. M., \& James, W. L. (1995) . Creativity vs. effectiveness? An integrating classification for advertising. Journal of Advertising Research, 35(6), 29-39.

Krugman, H. E. (1972). Why three exposures may be enough. Journal of Advertising Research, 12(6), 11-28.

Lee, Y. W., \& Mason, C. (1999). Responses to information in-congruency in advertising: The role of expectancy, relevancy, and humor. Journal of Consumer Research, 26(2), 156-169.

Loudon, D. L., \& Della Bitta, A. J. (2002). Consumer behavior: Concepts and applications (4th $\mathrm{ed}$ ). India: Tata Mc-Graw Hill Inc.

Naples, M. J. (1997). Effective frequency: Then and now. Journal of Advertising Research, 37(4), 7-12.

Pechmann, C., \& Stewart, D. W. (1989). Advertising repetition: A critical review of wearin and wearout. Current Issues and Research in Advertising, 11(1-2), 285-330.

Pelsmacker, P. D. (1998). Feelings evoked by warm, erotic, humorous or non-emotional print advertisements for alcoholic beverages. Academy of Marketing Science Review, 19(1), 1-32.

Sawyer, A. G. (1981). Repetition, Cognitive Response, and Persuasion, In. R.E. Petty, T. M. Ostrom, and T. C. Brock (Eds), Cognitive Responses in Persuasion. Hillsdale, NJ: Erlbaum

Stone, G., Besser, D. \& Lewis, L. E. (2000). Recall, liking, and creativity in tv commercials: A new approach. Journal of Advertising Research, 40(3), 7-18.

Tellis (1997). Effective frequency: One exposure or three factors? Journal of Advertising Research, 37(4), 75-80.

Till, D. B., \& Baack, W. D. (2005). Recall and persuasion: Does creative advertising matter? Journal of Advertising, 34(3), 47-57. 